$$
\begin{aligned}
& \text { الأهمية النسبية للطرق الإرشادية المستخدمة في إنتاج } \\
& \text { وتسويق محصول الكاكى بمحافظة الاقهلية } \\
& \text { عصام فتحي الزهار' ، ساميه محمد عبد الرحمن' ، جهاد بشرى ميخائيل' } \\
& \text { ا ـ ـ معه بحوث الارثاد الزراعي والتنمبة الريفية - مركز البحوث الزراعية - جيزة }
\end{aligned}
$$

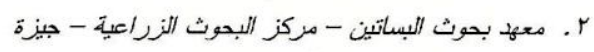

$$
\begin{aligned}
& \text { 1) } \\
& \text { أستهدف هذا البحث تحديد الأهمية النـــبية للطــرق الإرشــادية }
\end{aligned}
$$

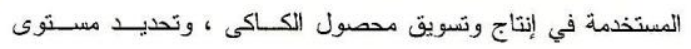

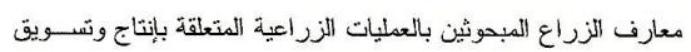

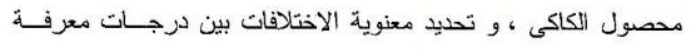

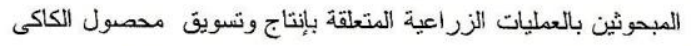

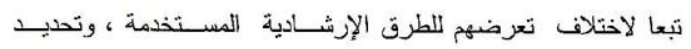

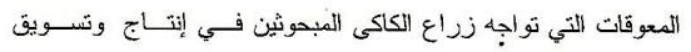

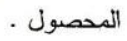

$$
\begin{aligned}
& \text { أجريت هذه الدراسة بمحافظة الدقهلية لكونها أكبر محافظات }
\end{aligned}
$$

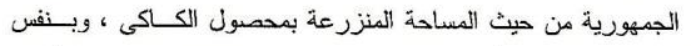

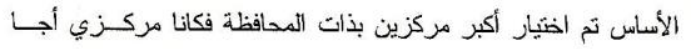

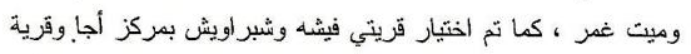

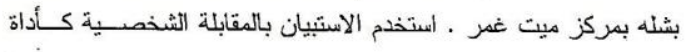

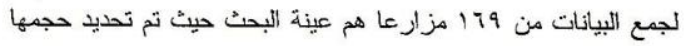

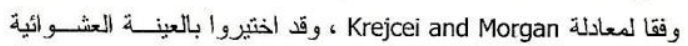

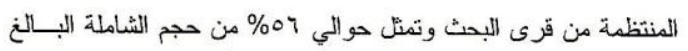

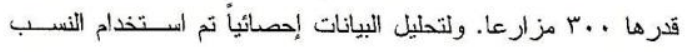

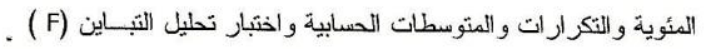

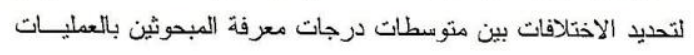

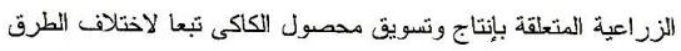

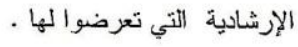

$$
\begin{aligned}
& \text { وتمثلت أهم النتائج البحثية فيما يلي : أبئية }
\end{aligned}
$$

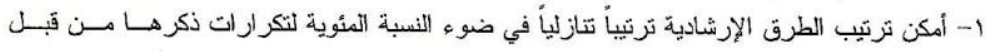

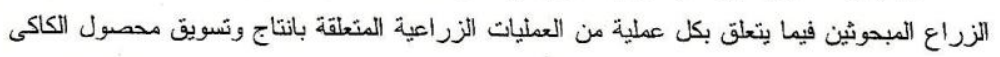




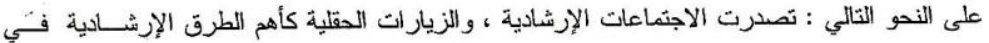

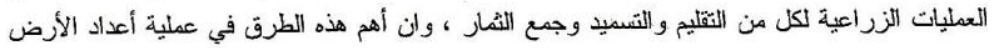

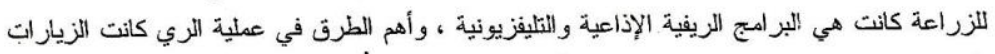

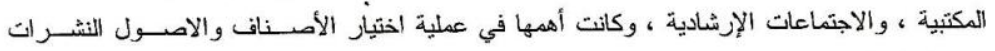

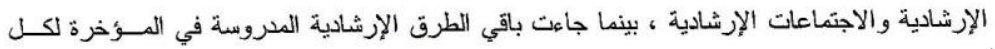

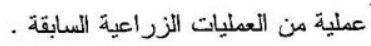

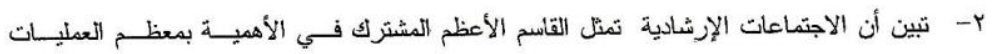

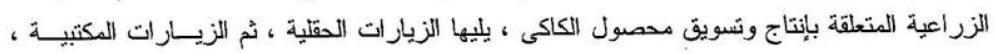

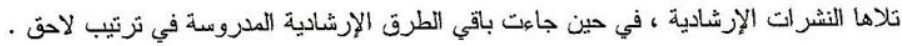

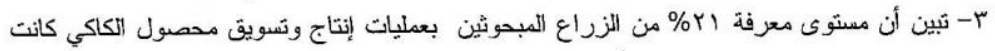

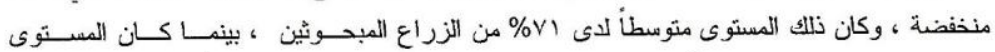

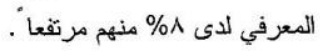

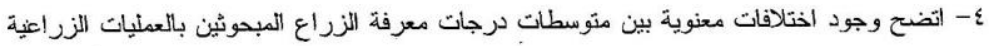

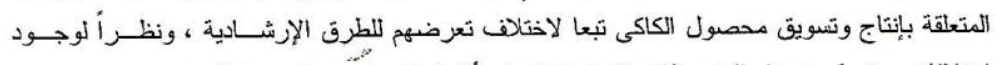

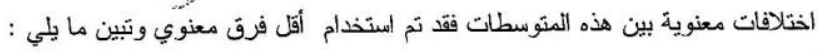

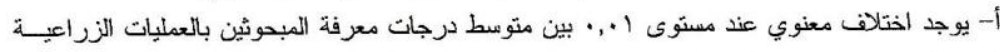

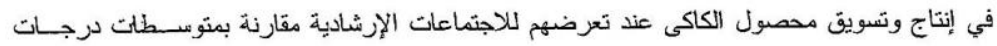

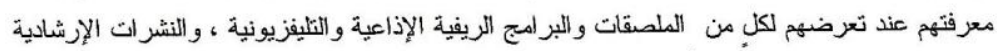

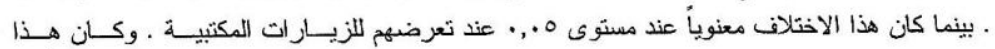

الاختلاف غير معنوي عند تعرضهم للزيارات الحقلية .

ب- يوجد اختلاف معنوي عند مستوى | •, • بين متوسط درجات معرفة المبحوثين بالعمليات الزر اعيــة

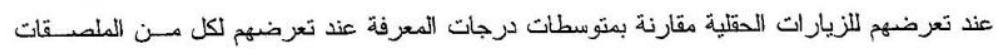

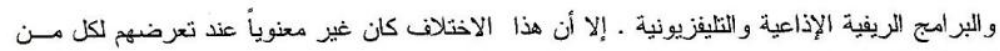

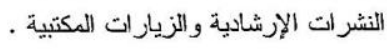

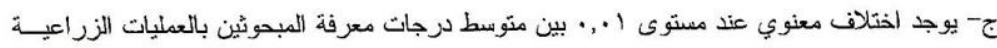

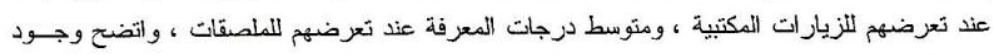

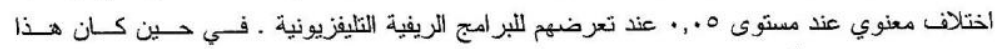

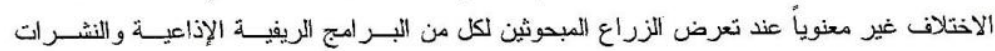

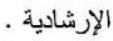

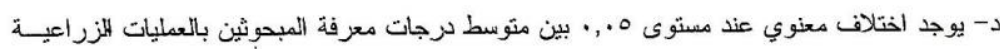

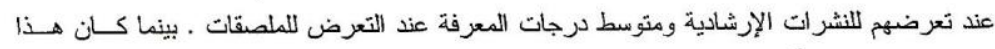

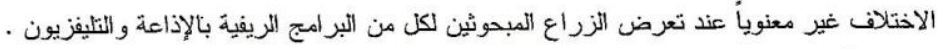

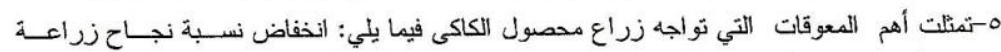

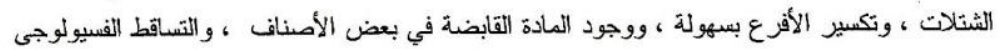


للثمار ، وإصابة الثمار بضربة الثمس ، و ارتفاع أسعار الأسمدة والمبيدات الزر اعية ، والإصابة بذبابة

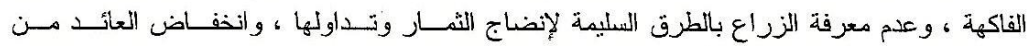
المحصول .

المقدمة والمشكنة البحثية

يعثبر الإنتاج الفاكهي في دصر جانب أساسي في الإنتاج النباتي والغذائي للإنســان و الــذئي

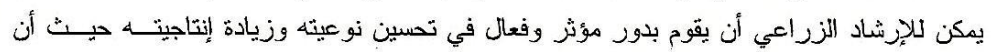

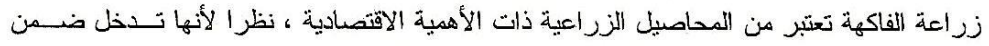

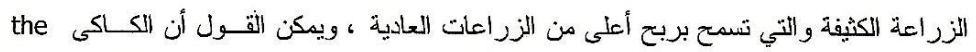
ppersimons

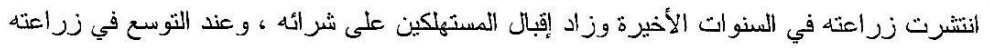

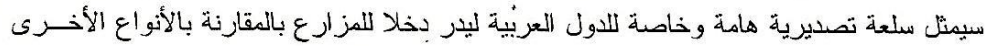

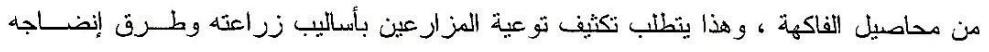

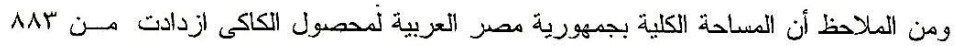

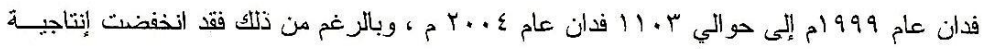

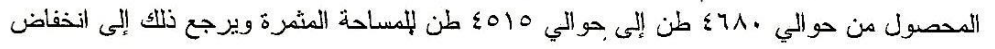

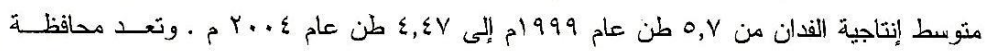

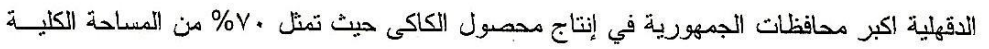

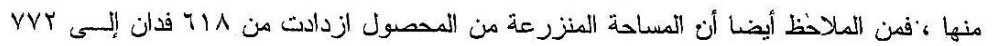

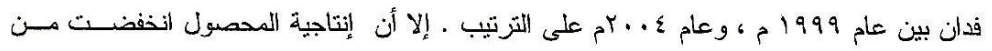

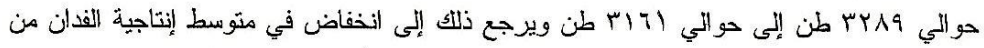

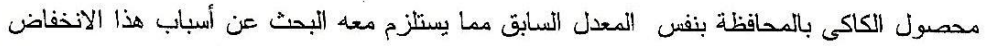

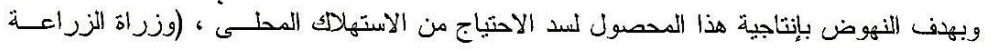

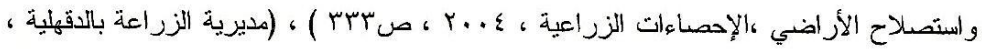

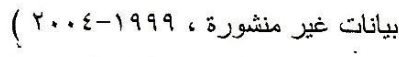

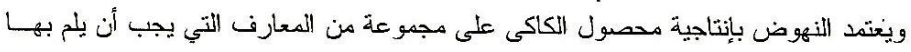

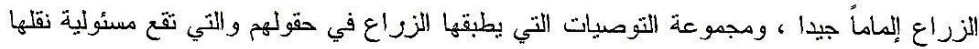

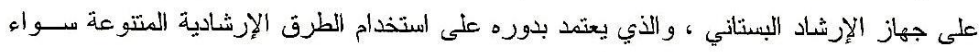

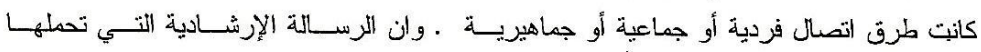

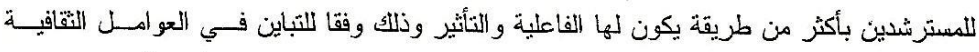
و الاجتماعية والاقتصادية والتنظيمية المؤثرة على العمل الإرشادي ، وكنلك تنوع الأهدات التعليمية

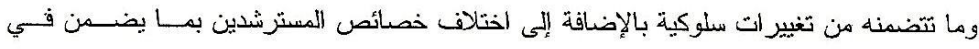

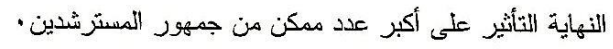




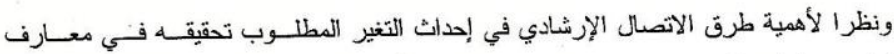

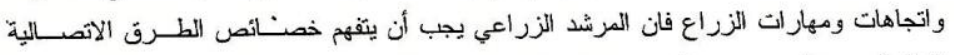

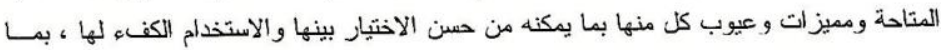

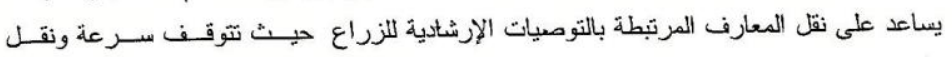

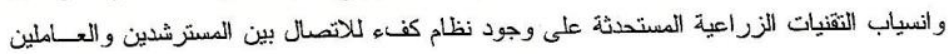

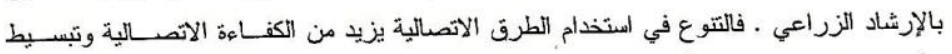

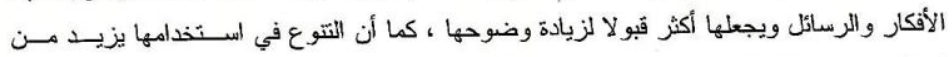

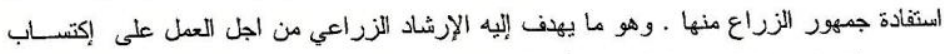

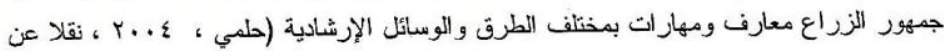

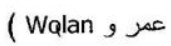
ومن خلال ما سبق عرُضه عن انخفاض إنتاجية محصول الكاكى فى السنوات الماضية المذكورة

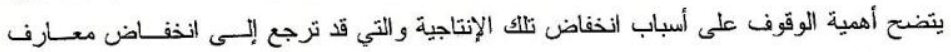

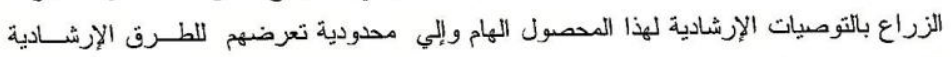

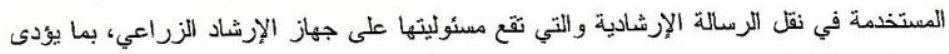

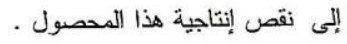

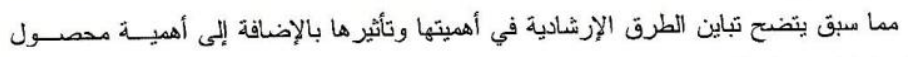

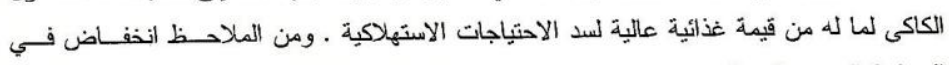

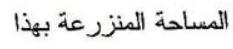

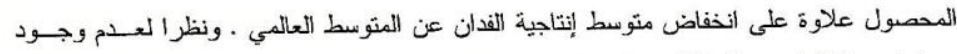

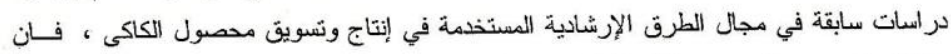

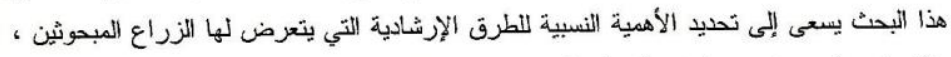

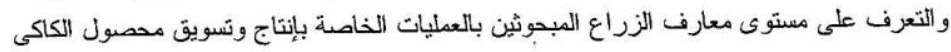

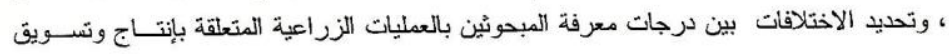

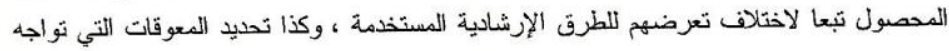

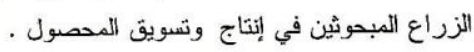

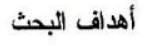

ا-تحديد الأهمية النسبية للطرق الإرشادية المستخدمة في إنتاج وتسويق محصول الكاكى في منطقة

$$
\text { البحث }
$$

rا-تديد مستوى معارف الزراع المبحوثين بالعمليات الزراعية المتعلقة بإنتاج وثشويق محصــول

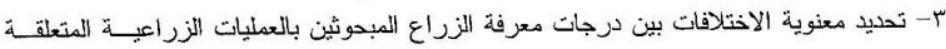

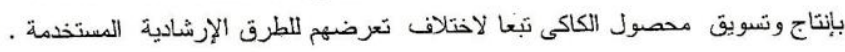

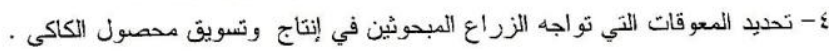




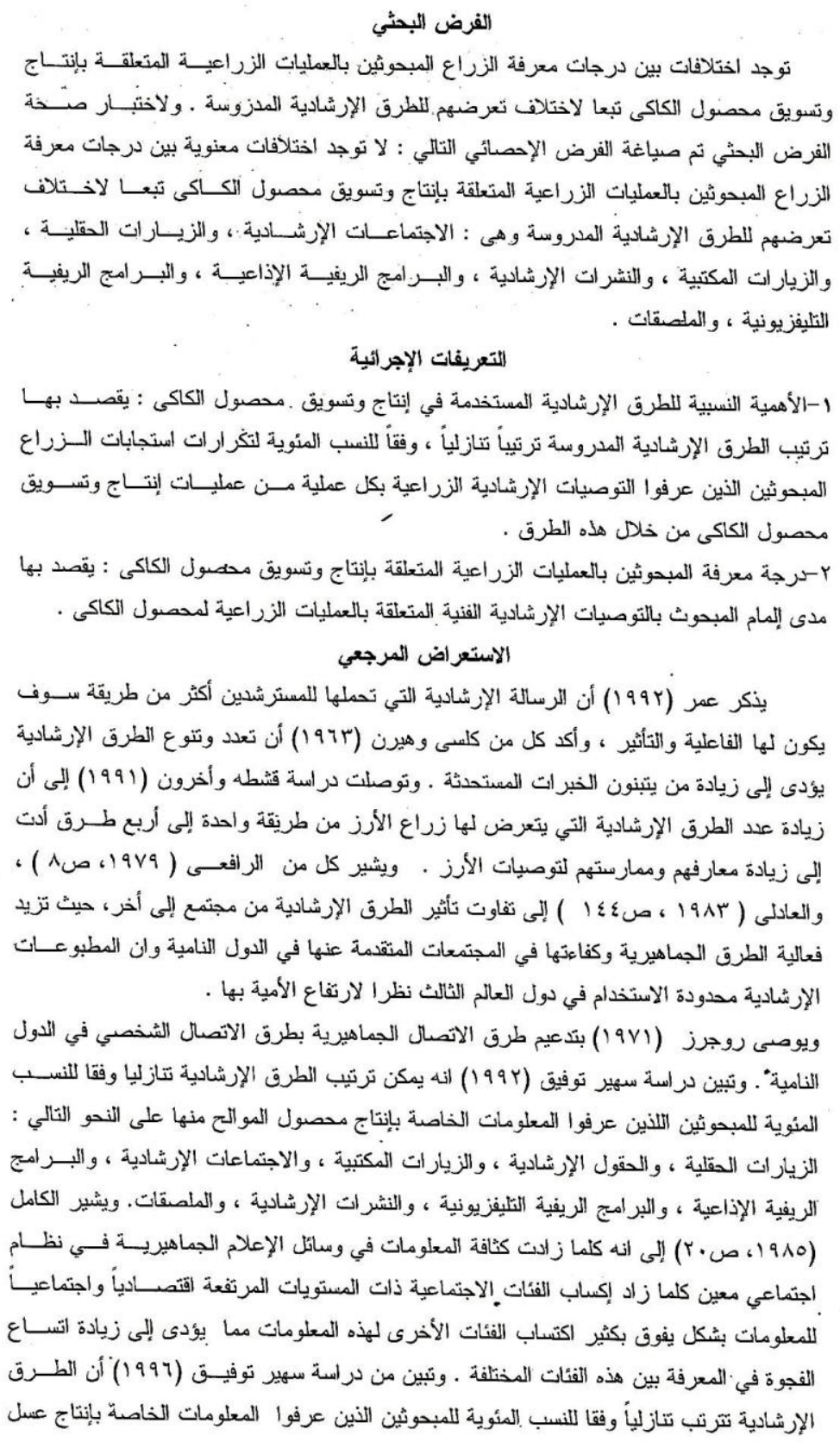




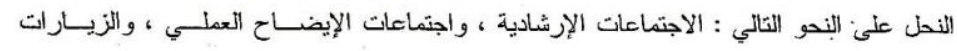

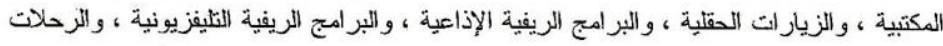

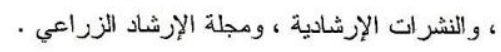

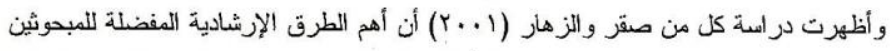

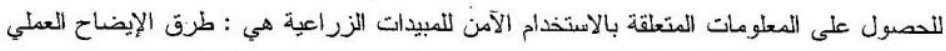

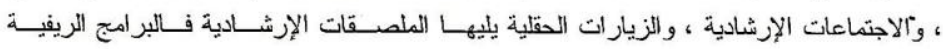

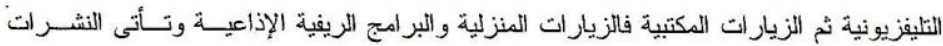
الإرشادية ومقالات الصحف و المجلات الإرشادية في المرتبة الأخيرة .

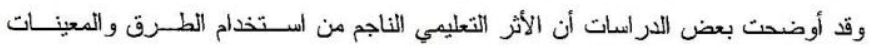

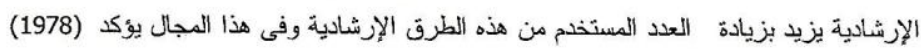
Mosher

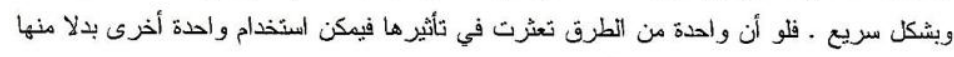

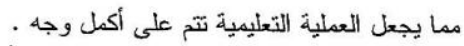

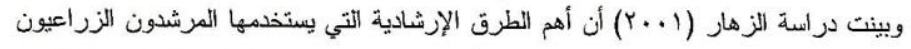

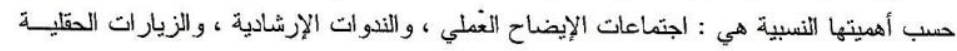

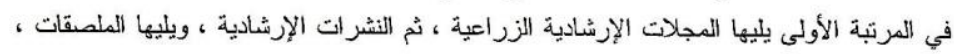
ثُم الزيار ات المكتبية .

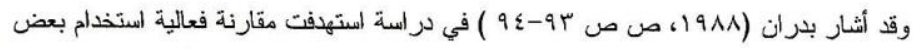

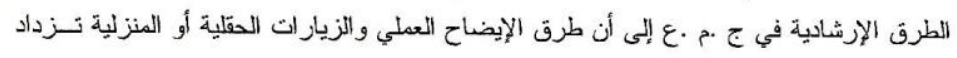

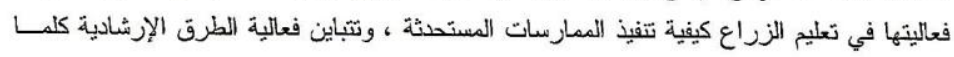

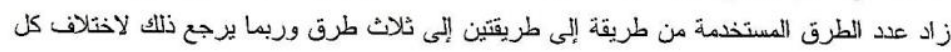
طريقة في طبيعتها عن الطرق الأخرى .

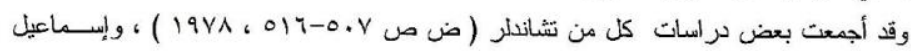

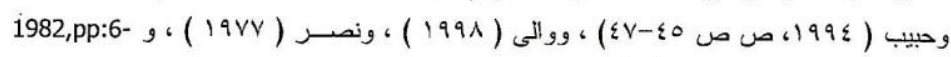

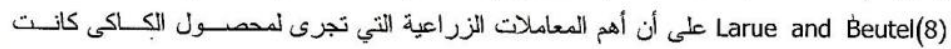
كالتالي : 1- الزر اعة ومسافات الزراعة : حيث تزرع شتلات الكاكى المطعومة في بداية الزبيع ملثا ويجب

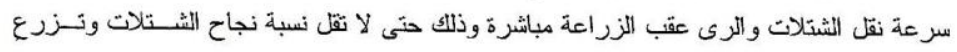

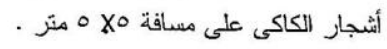
ب- نقليم وتربية أشجار الكاكى : يفضل تربية أشجار الكاكى بطريقة القائد الوسطى المحور لأنهـا

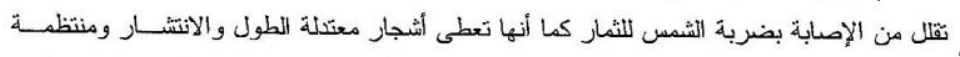

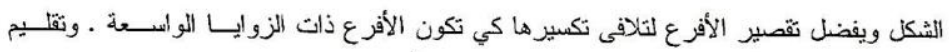

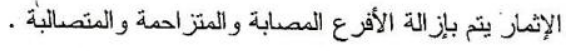




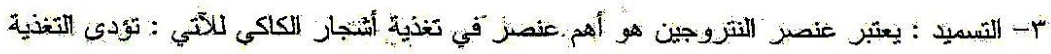

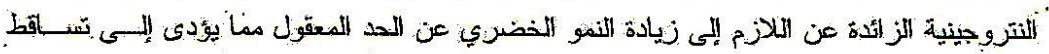

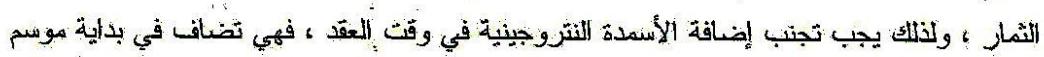

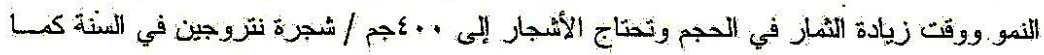

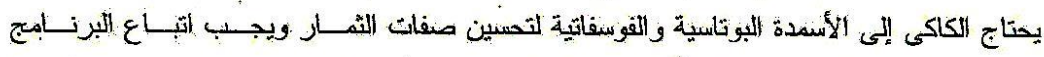

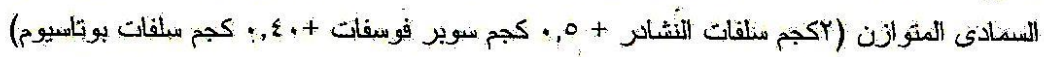

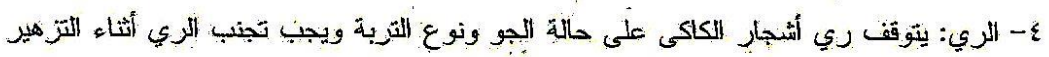

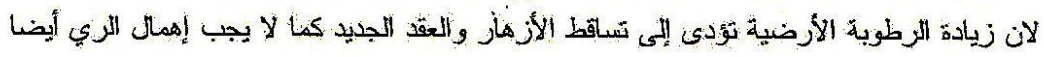

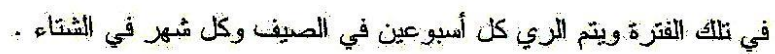

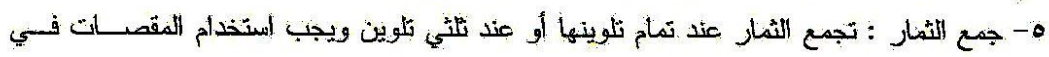

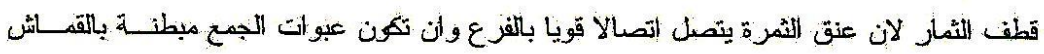

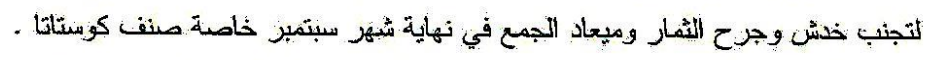

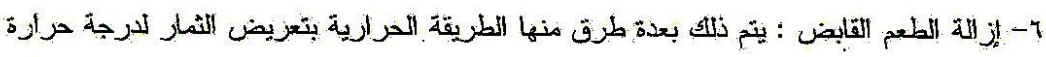

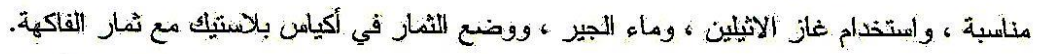

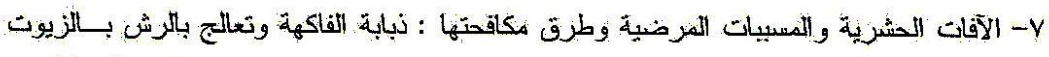

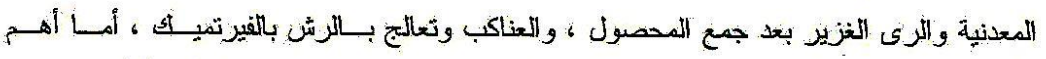

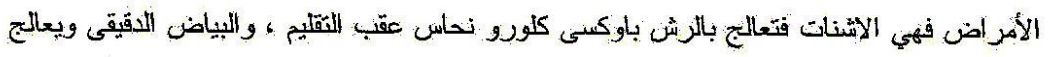

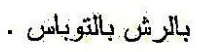

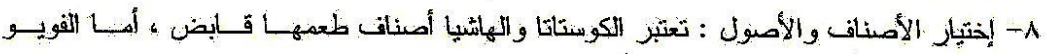

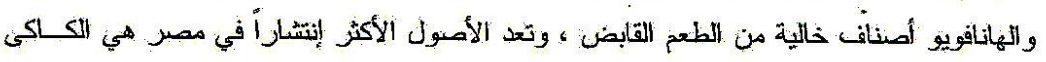

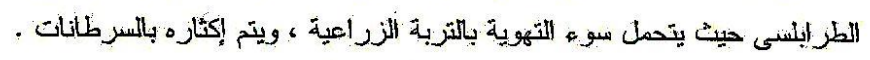

$$
\text { الأسلوب البحثي }
$$

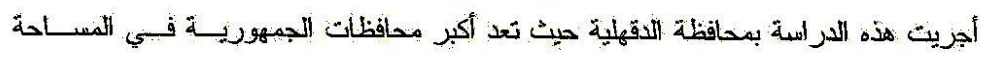

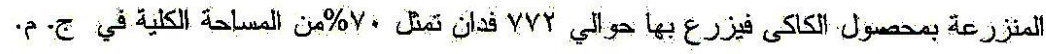

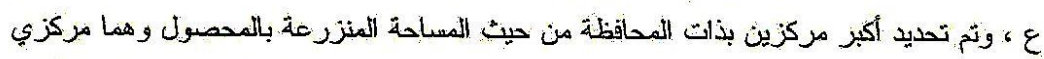

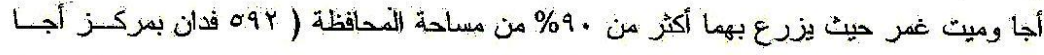

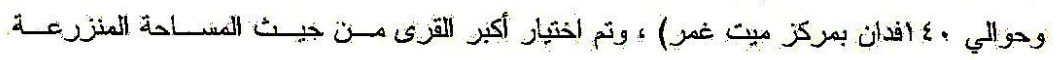

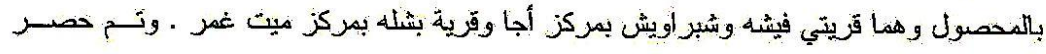

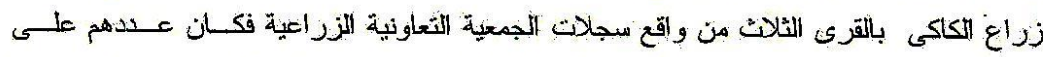

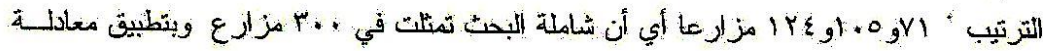
Krejcei and Morgan (1970, pp: 607-608)

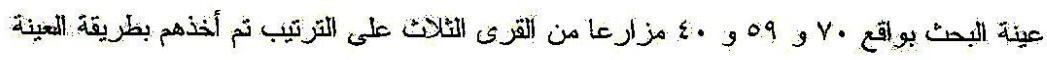

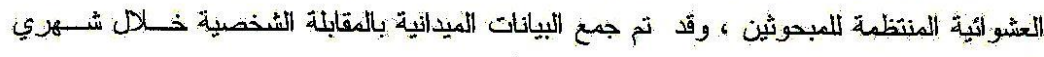

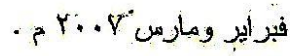




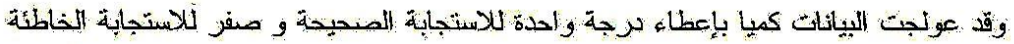

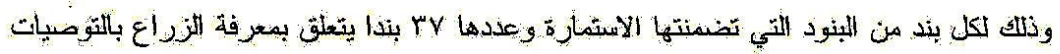

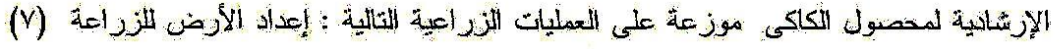

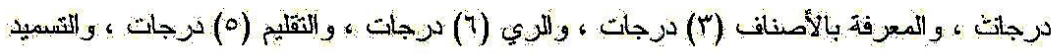

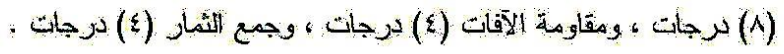

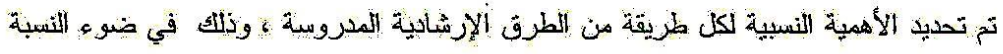

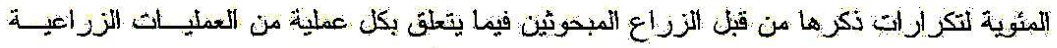

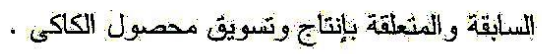

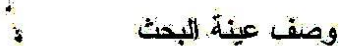

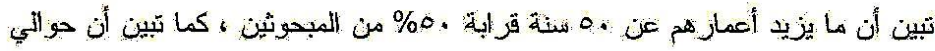

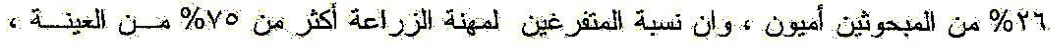

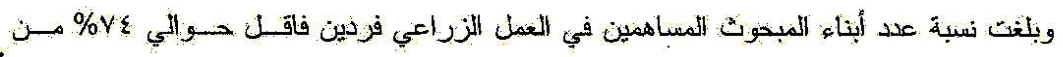

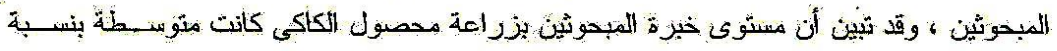

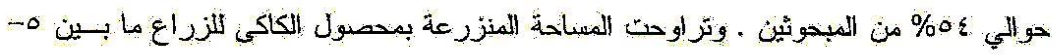

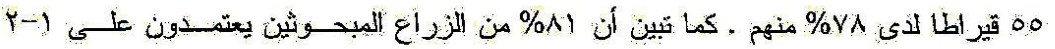

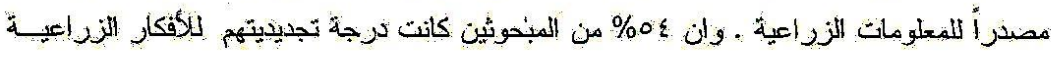

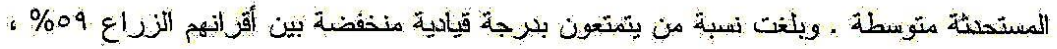

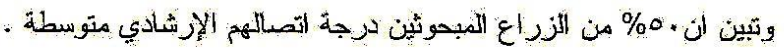

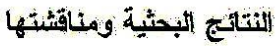

أو لا: تصني الأهمية النسنية للطرق الإرشادية المسنخدمة في إنتاج وتسويق محصول الكاكى

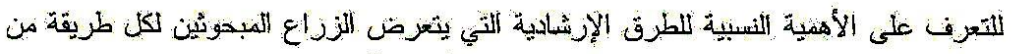

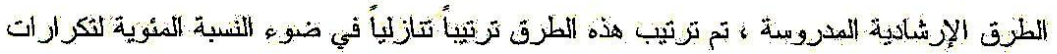

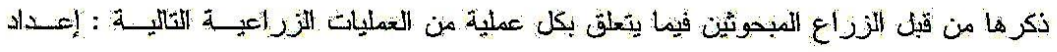

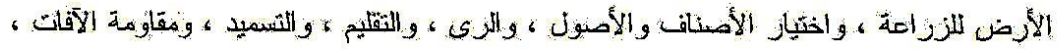

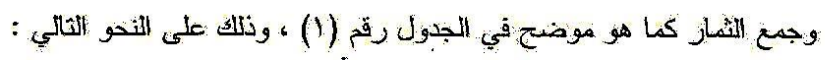

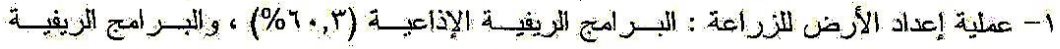

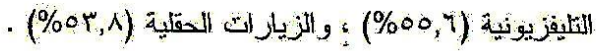

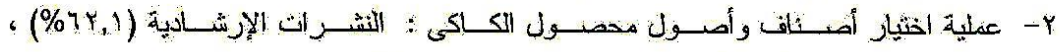

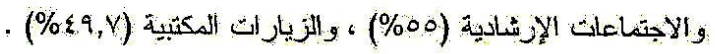

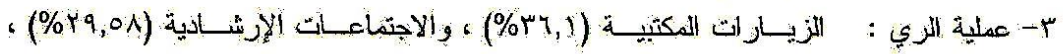

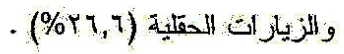

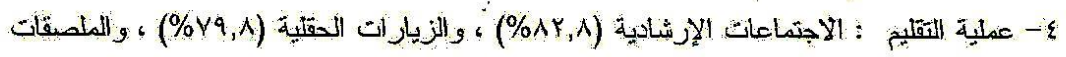




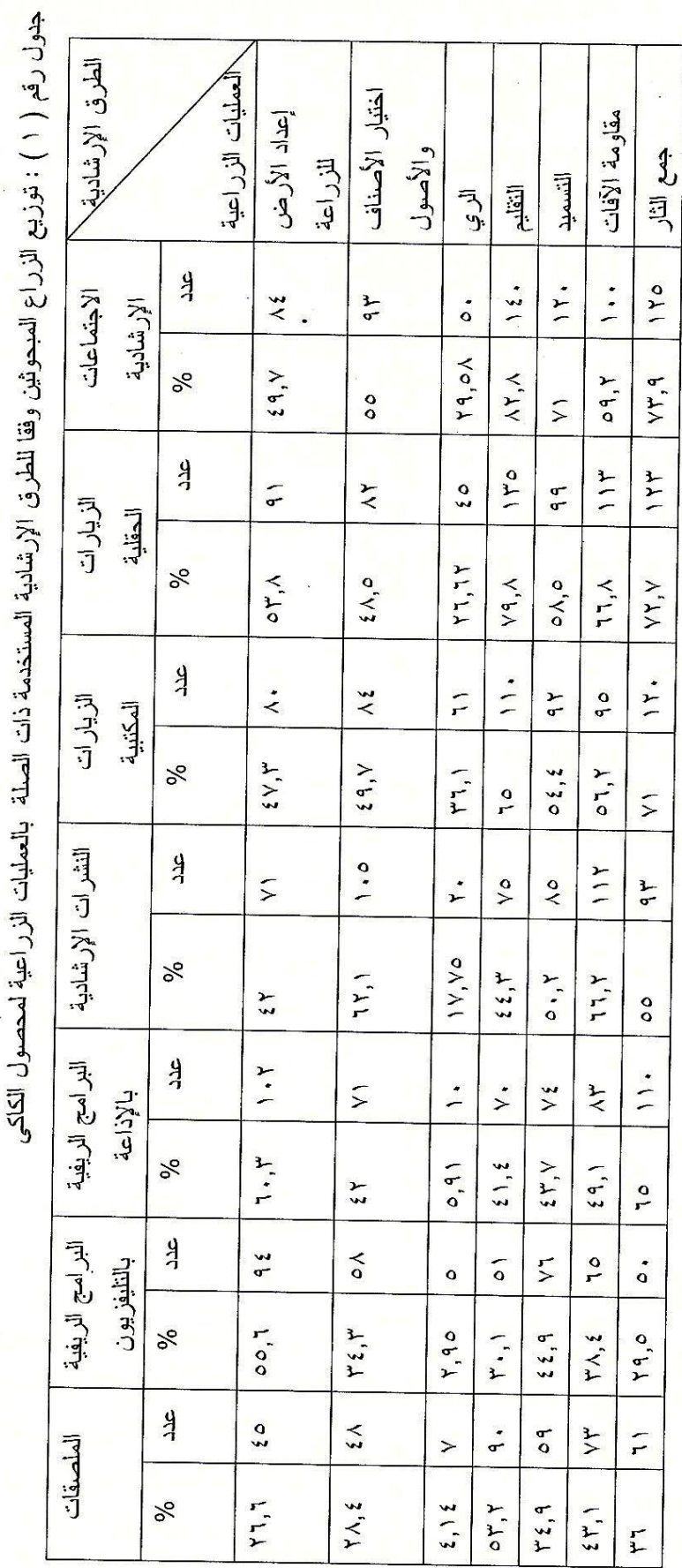




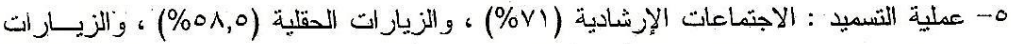

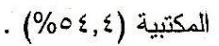

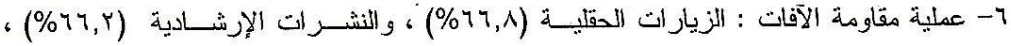

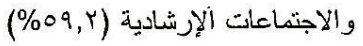

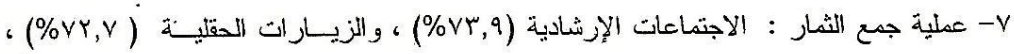

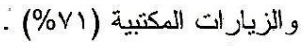
ويلاحظظ مما سيق ، أن الاجثماعات الإرشادية تمثل القاسم الأعظم المشترك في الأهمية لمعظم

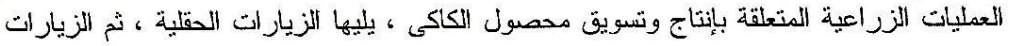

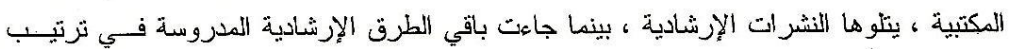
لاحق .

ثاتيا : مستوى معرقة المبحوثين بالعمليات الزراعية المتعثقة بإنتاج وتسويق محصول الكاكى :

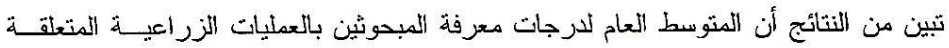

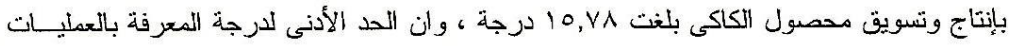

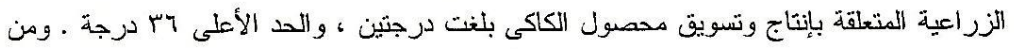

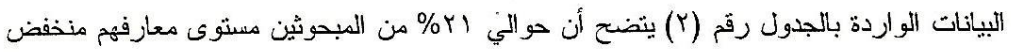

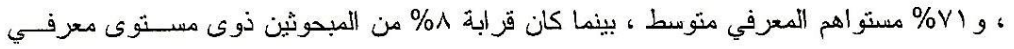
مرتفع بالعمليات الزر اعية المتعلقة بإنتاج وتسوبق محصول الكاكى وتعكس هذه النتائج وجود احتباج معرفي إرشادي بالتوصيات الإرشادية المنلى لانتاج وتسويق محصول الكاكى ، مما يحتم ضــرورة

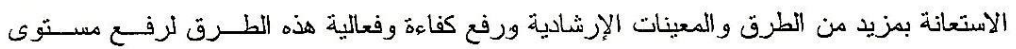

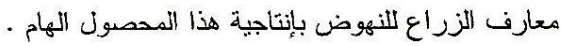
جدون رقم (Y) : نوزيع الزراع المبحوثين وفقا لمستوى معرفتهم بالعمليات الزر اعية

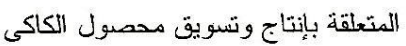

\begin{tabular}{|c|c|c|c|}
\hline$\%$ & العدد & \multicolumn{2}{|c|}{ المستوى المعرفي } \\
\hline$r, V$ & ro & ץ-سו درجة & منخفض \\
\hline VI & Ir. & ع ا-Oب درجة & مثوسط \\
\hline$\Lambda, r$ & $1 \varepsilon$ & צץ-צr درجة & هرثفع \\
\hline $1 \ldots$ & 179 & & المجموع \\
\hline
\end{tabular}

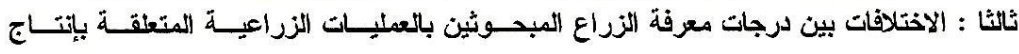
وتسويق محصول الكاكى تبعا لاختلاف تعرضهم للطرق الإرشادية المستخدمة :

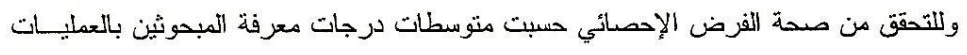
الزر اعية في إنتاج وتسويق دحصول الككى ثبعا لاختلاف تعرضهم للطرق الإرشادية المســتخدمة

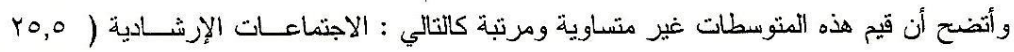

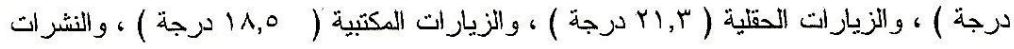




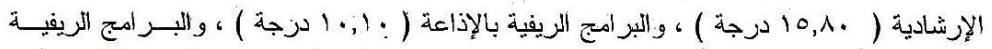

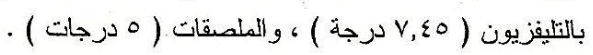

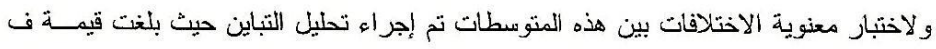

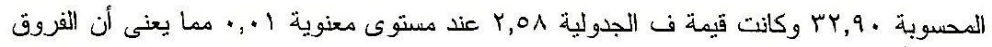

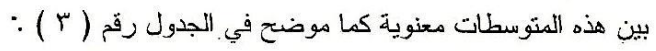

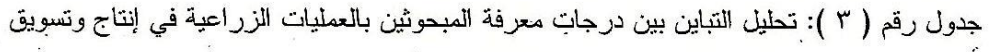
محصول الكاكى تبعا لاختلاف تعرضهم اللطرق الإرشّادية

\begin{tabular}{|c|c|c|c|c|}
\hline قيمة فـ & دالانحر افات مربع & الانحر افات مربع & درجات الحرية & مصدر التباين \\
\hline$* * \Psi, Y, q$ & $\begin{array}{l}Y 011,00 \\
V 7,0 \leqslant\end{array}$ & $\begin{array}{l}q, \neg 7 \vee, \wedge \\
1 r r q 9, \varepsilon \wedge\end{array}$ & $\begin{array}{c}7 \\
1 \pi r \\
\end{array}$ & داخل الطرق الطرق \\
\hline & & $1 \cdot r \cdot T V, r \wedge$ & 171 & المجموع \\
\hline
\end{tabular}

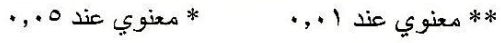

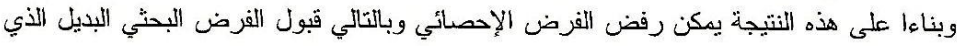
يوضح وجود اختلافات معنوية بين متوسطات درجات معرفة المبحوثين بالعطليات الزراعية واعية المنعلقة

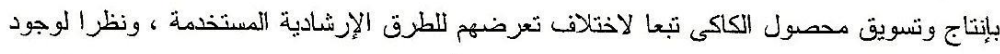

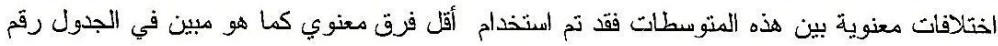

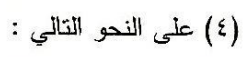

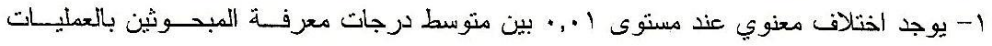

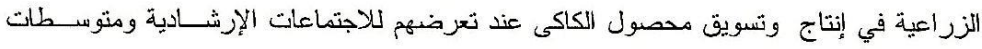
درجات المعرفة عند التعرض لكل من الملصقات ، و البرامج الريفية بكل من الإذاعة و التليفزيون

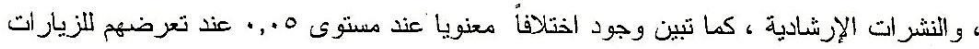

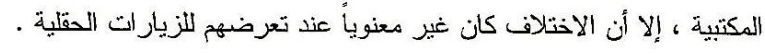

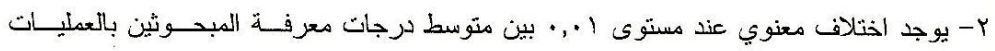

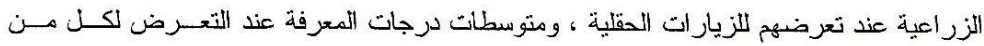

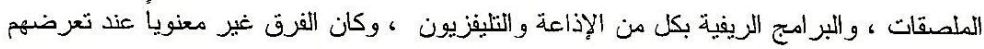

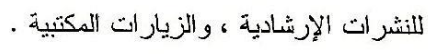

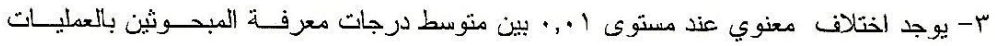

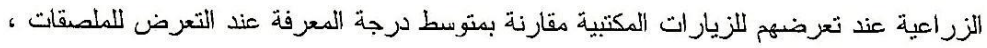

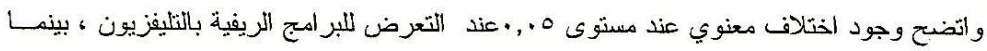

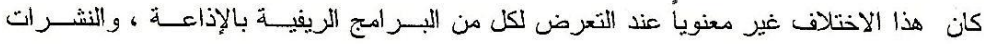


ع- يوجد اختلاف معنوي عند دستوى ه . , · بين متوسط درجات معرفـــة المبحــوثين بالعمليـات

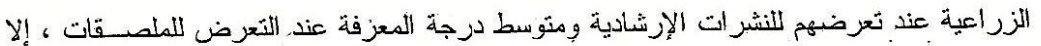

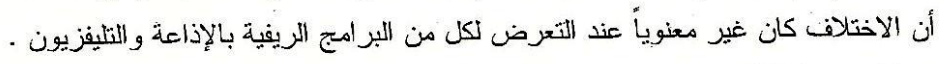

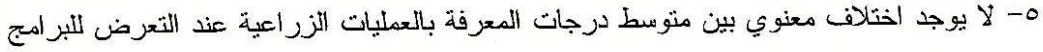
الريفية بالإذاعة وكل من متوسط درجة المعرفة عند التعرض لكل من الملصقات ، و البرامج الريفية

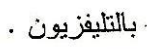
4- لا يوجد اختلاف دعنوي بين منوسط درجات المعرفة بالعمليات الزر اعية عند التعرض للبر امج

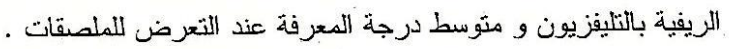

جدول رقم (ع): معنوية الاختلافات بين درجات معرفة المبحوثين بالعمليات الزر اعبة المتعلقة بإنتاج وتسويق محصول الكاكى تبعا لاختلاف نعرضهم للطرق الإرشادية المستخدمة لرنية

\begin{tabular}{|c|c|c|c|c|c|c|c|c|c|}
\hline \multicolumn{2}{|c|}{ كير الكل فرق دمنوي } & \multirow{2}{*}{ |الإرشادية | الإتماعات } & \multirow{2}{*}{ 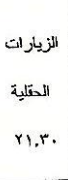 } & \multirow{2}{*}{ الزكتبية } & \multirow{2}{*}{ الإلرشادية } & \multirow{2}{*}{ بالرالبانية } & \multirow{2}{*}{ 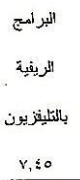 } & \multirow{2}{*}{ المصتات } & \multirow{2}{*}{ الطرق الارثشايدية المستخدمة } \\
\hline$\ldots$ & $\ldots \circ$ & & & & & & & & \\
\hline $\mid r, 1$. & $9, Y)$ & صفر & $\{, 0$ & v,r. & $\cdot \bullet_{4, \mathrm{v}}$ & $\cdots 10,6$ & $\cdots 10, .0$ & $\ddot{*} r,, \circ$ & الاجتماعات الإرشانية Y0,0 Y \\
\hline $1, i v$ & $\lambda, 11$ & & صنر & $r, r$. & $0, r$. & $\cdots, ., 9$ & $\cdots, r, 00$ & $\cdots 17$ & 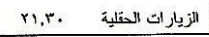 \\
\hline $1+, \varepsilon \varepsilon$ & $\cdots, 1, x$ & & & صنر & r.v & $\lambda, \varepsilon$. & $* 11, .0$ & $* *$ * & 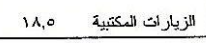 \\
\hline Ir.ru & $1 ., 1 r$ & & & & صنز & $0, \%$ & $\lambda_{1}, \mathrm{rO}_{0}$ & $\bullet \cdots, \lambda$ & 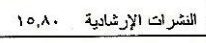 \\
\hline $14 . . v$ & $9,9 r$ & & & & & صنز & 1,10 & 0.1. & البرايج الريفية بالاداعة. ., .. \\
\hline$\lambda, V_{4}$ & ד. & & & & & & 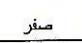 & r.io & 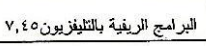 \\
\hline & & & & & & & & صنر & اللمصقات \\
\hline
\end{tabular}

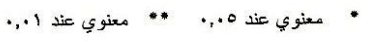

خامسا :المعوقات التي تواجه الزراع المبحوثين في إنتاج وتسويق محصول الكاكى :

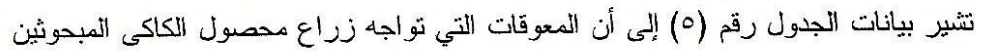

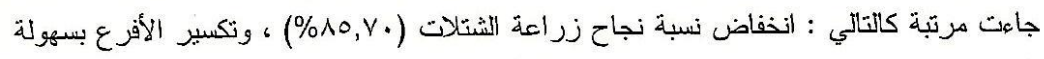

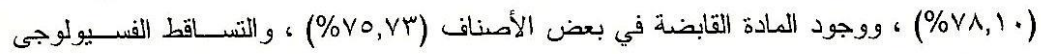

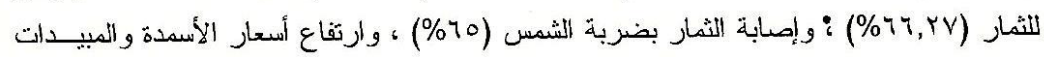

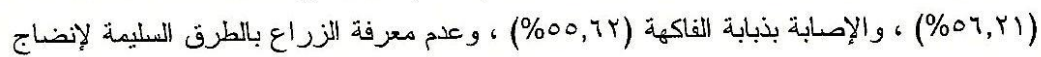

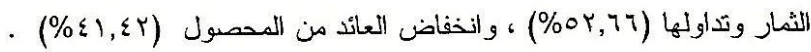

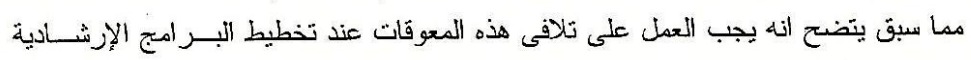

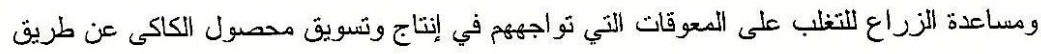


جهاز الإرشاد الزراعي البستاني المعنى بذلك واقتراح الحلول المناسبة للحصول على الشتلات من

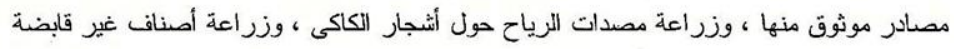

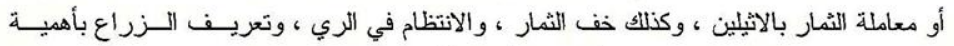

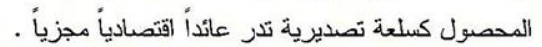

جدول رقم (ه) : توزيع الزراع المبحوثين وفقا للمعوقات الثي تو اجههم في إنتاج وتسويق محصول الكاكى

\begin{tabular}{|c|c|c|}
\hline$\%$ & $\begin{array}{c}\text { ع } \\
\text { عد } \\
179=\end{array}$ & 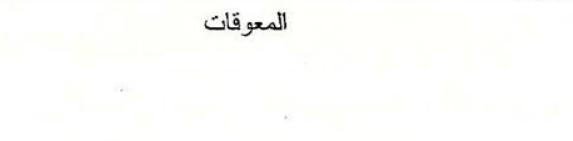 \\
\hline$\wedge 0, \mathrm{~V}$. & $1 \leqslant 0$ & 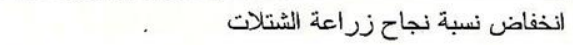 \\
\hline$\vee \wedge, 1$. & re & تكسير الأفرع بسهولة \\
\hline Vo,Vr & Irs & وجود المادة القابضة في بعض الأصناف \\
\hline $7 T, Y V$ & 114 & التساقط الفسيولوجى للثمار \\
\hline $10, \ldots$ & 11. & إصابة الثمار بضربة الشمس \\
\hline $0 Y, Y_{1}$ & 90 & ارتفاع أسعار الأسمدة والمبيدات \\
\hline $00, \pi$ & $9 \varepsilon$ & الإصابة بذبابة الفاكهة \\
\hline Or, 17 & 19 & عدم معرفة الزراع بالطرق العليمة لإنضاج الثمار وتداونها \\
\hline$\varepsilon 1, \varepsilon Y$ & v. & انخفاض العائد من المحصول \\
\hline
\end{tabular}

. التوصيات

في ضوء ما أسفر عنه البحث من نتائج ، فانه يمكن استخلاص التوصيات التالية :

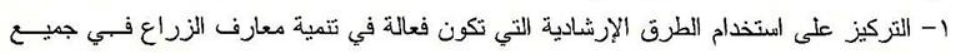

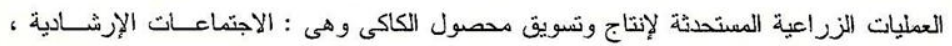

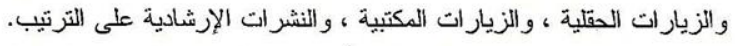

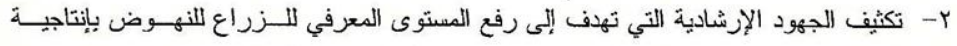

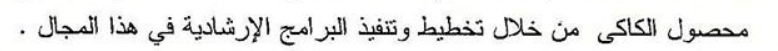

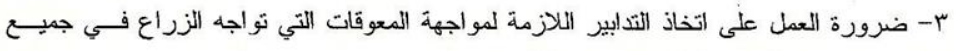
مر احل الإثتاج و التسويق لهذا المحصول الهام . 
المراجع

1- إسماعيل ، زكريا ، وهدى حبيب ، الممارسات السمادية في بساتين أشجار الفاكهة بالو ادي وجنوب الالثتا ، الإدارة العامة للتقافة الزر اعية ، نشرة فنية رقم ب ، ع99 1.

ب- الخولى ، حسين زكى ، ومحمد فتحي الشانلي ، الإرشاد الزر اعي ، كلية الزر اعــة ، جامعــة

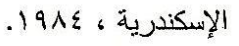

ب- الزهار ، عصام فتحي ، در اسة لبعض المتغير ات المتعلقة بمرشدي المراكز الإرشادية المـؤثرة على درجة استخدامهم للطرق الإرشادية بمحافظة كفر الثيخ ، نشرة بحتبــة رقـم ؟ب ، مركــز البحوث الزر اعية ، معهد بحوث الإرشاد الزر اعي و التتمية الريفية ، 1 . . . . ع- الر افعى ، احمد كامل ، مقارنة فعالية بعض الطرق الإرشادية في المناطق المنعزلة بو ادي رمــاح بالجمهورية العربية اليمنية ، نشرة بحثية رقم · 1 ، مركز البحوث الزراعية ، معهد بحوث الإرشاد الزر اعي و النتمية الريفية ، 19v9.

0- الشبراوى ، عبد العزيز حسن ، الطرق و المعينات الإرشادية في التعلبم الإرشادي ، الطبعة الأولى لى ، مركز البحوث الزر اعية ، معهد بحوث الإرشاد الزر اعي والتتمية الريفية ، 1919. 1 - العادلى ، احمد السيد ، أسابيات علم الإرشاد الزرراعي ، دار المطبوعات الجديدة ، الإســكندرية ، .1971

V- الكامل ، فرج ، تأثير وسائل الاتصال و الأسس النفسية والاجتماعية ، دار الفكر العربي ، القاهرة ،

^- بدران ، شكري محد ، دراسة مقارنة لفاعلية استخدام بعض استخدام بعض الطرق الإرشادية في

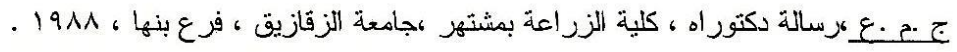
9- تشاندلر ، وليام هنري ، بساتين الفاكهة المنساقطة الأوراق (منرجم إلى العربية ) ، الطبعة الأولىى

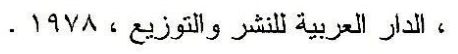

• 1- توفيق ، سهير توفيق ، دراسة الأهمية النسبية للطرق الإرشادية المستخدمة و.المفضلة في مجــال إنتاج محصول الموالح ، نشرة بحثبة رقم ץ +1 ، مركز البحوث الزٔر اعية ، معهد بحوث الإرشساد

$$
\text { الزر اعي و التتمية الريفية ، بو99. }
$$

1ا- توفيق ، سهير توفيق ، دراسة الأهمية النسبية للطرق الإرشادية المستخدمة و المفضلة في مجـال إنتاج عسل النحل نشرة بحثية رقم ؛ ، الجمعية العلمية للإرشاد الزر اعي ، 1997 ـ 
ب ا- حلمي ، احمد فؤاد حسن ، دراسة معارف وتتفيذ ممارسات زر اع القول السوداني المستقاة مــن

الطرقي الإزشادية المستخدمة في برنامج النهوض بمحصول الفول السودانحي ببعض قـري منطة

البستان في مركز الدلنجات بمحافظة البحيرة ، المجلد ro ، عدد r ، المجلة المصسرية للبحسوث

الزر اعية ، مركز البحوث الزراعية ، ع. . ب .

بر- هقر ، زغلول محمد ، و عصام فتحي التزهار ، أثر بعض العو امل على استخدام الزر اع الآمن

للمبيدات الزر اعية فيه بعض قرى مركزي بيلا وكفر الثبخ بمحافظة كفر الثيخ ، المجلد YV ، عدد

$$
\text { ع ، مجلة البحوث الززر اعية" ، جامعة طنطا ، 1 . . . . }
$$

ع ا- عمر ، احمد محمد ، الإزثاد الزرر اعي المعاصر ، ممر للخدمات العربية ، القاهرة ، ب99 19.

ه - كلسى ، لنكونن دافيد و كانون تشايلز هبرن ، الإرشاد الزر اعي ، ترجمة محمـد المعلـم ، دار

$$
\text { النهضة المصرية ، القاهرة ، بr79 1. }
$$

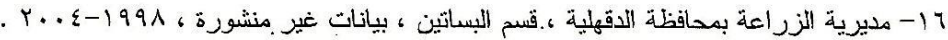

Yا- نصر ، طه عبد الله ، الإنتاج الفكهي في 'لموطن المعربي، الفو اكه المتسـاقطة الأوراق ، دار

المعارف ، الإسكندرية ، I9VV

^ا- و التى ، عبد الفتاح سليمان ، زير اعة وانتاج الكاكي ، الإدارة العامة للتقافة الزر اعية ، النشــرة

$$
\text { الفنية رثم 1991 ، }
$$

و ا- وز ارة الزر اعة واستصلاح الأر اضغي ، فطاع الثئون الاقتصادية ، الإحصاءات الزر اعيـة ،

$$
\text { . Y.. }
$$

20- Krejcei, R .V and D.W. Morgan. 1970. Determining sample size for research activities educational and psychological measurement, college station Urham, north Carolina .

21- Larue, J.H., K.W. Opitz and J.A. Beutel. 1982. Growing persimmon division of science, university of California, leafelt 21277 ,

22- Mosher, A .T., 1978. An introduction to agricultural extension , Agricultural Council, New York. 


\title{
RELATIVE IMPORTANCE OF UTILIZED EXTENSION METHODS TO PERSIMONSE PRODUCTION AND MARKETING IN DAKAHLIA GOVERNORATE
}

\author{
ELZAHAR, E. F. ${ }^{1}$, SAMIA. M.ABD -ELRAHMAN ${ }^{1}$ AND GEHAD B.MIKHAEL ${ }^{2}$
}

1. Agricultural Extension \& Rural Development Research Institute, $A R C$, Giza

2. Horticultural Research Institute, ARC, Giza

(Manuscript received 3 March 2008)

\begin{abstract}
The study aimed at determining the relative importance of utilized extension methods, and determining the knowledge degree regarding respondents of agricultural processes of Production and marketing of The persimonse crop, also determining the differences between agricultural processes knowledge means, due to their exposure to various utilized extension Methods, and identifying the constraints facing farmers of the persimonse crop.

Data were collected from 169 persimonse farmers as random sample in three villages which were Fesha, Sobrawesh at Aga distract and Beshla at Meetghamr distract in Dakahlia governorate . Data were analyzed statistically by using percentages, frequencies, means, and analysis of variance $F$ ratio which were data analysis .
\end{abstract}

The results of this study showed that:

1 -The important extension methods during the agricultural processes were extension meetings and field visits are at pruning, fertilization and harvesting . the radio and T.V rural programs at tillage. While office calls and extension meetings are at irrigation. In addition to extension publication and extension meetings are at selection of varieties.

2 - The important extension methods was ranked due to their relative importance as follows : extension meetings, field visits, office calls, extension publications.

3 - The knowledge level regarding agricultural processes was moderate for $71 \%$ of respondents, while this level was high for $8 \%$ only.

4 -There was significant differences between the means knowledge degree of agricultural processes due to exposure to extension methods:

- There was significant differences between the means knowledge degree during exposure to extension meetings and the means knowledge degree during exposure of both posters and T.V and radio rural programs, extension publication, and field meetings .

-There was significant differences between the mean knowledge degree during exposure to office calls and the mean knowledge degree during exposure of both posters and T.V and radio rural programs.

- There was significant differences between the mean knowledge degree during exposure to office calls and the mean knowledge degree during exposure of both posters and rural T.V programs.

- There was significant differences between the mean knowledge degree during exposure to extension publication and the degree knowledge mean during exposure to posters .

5 - The important constraints facing persimonse farmers were ranked as follows : low survival of transplanting , easy of branches breaking, astringency, physiological fruits drop , fruit sunstroke, high prices of fertilizers and pesticides, fruit infection with fruit fly, of unawareness persimmon farmers for fruit induction and remove of astringency process and handling , and low income. 